\title{
APRESENTAÇÃO
}

PRESENTATION

\section{DOSSIÊ: DE(S)COLONIZANDO A PANDEMIA}

\section{Jean Segata (UFRGS, Brasil) \\ Rozeli Porto (UFRN, Brasil) \\ Andrea Mastrangelo (UNSAM/CONICET, Argentina)}

Vírus são informantes privilegiados numa pandemia, mas o desafio que traçamos para este dossiê foi o de escrever histórias para além deles. Na esteira de recentes trabalhos que temos desenvolvido, entendemos que a pandemia é um evento múltiplo e desigual e que excede as narrativas globais centradas no patógeno (SEGATA, 2020; SEGATA; SCHUCH; DAMO; VÍCTORA, 2021; GAMLIN; SEGATA; BERRIO; GIBBON; ORTEGA, 2021). Distinções socioeconômicas, culturais, políticas, ambientais, coletivas ou mesmo individuais tensionam a homogeneidade do risco, da doença e do cuidado. Há sempre um emaranhado mais ou menos contingente que estabelece condições favoráveis para que eventos como este ganhem forma, extensão e intensidade (SEGATA; SCHUCH; DAMO; VÍCTORA, 2021). É claro que conhecer o agente patógeno, sua dinâmica de infecção e de evolução é decisivo, mas a sua superexposição costuma desviar a atenção das combinações nocivas que envolvem diretamente agentes políticos e corporativos, desmonte de políticas sociais e relações históricas de poder e desigualdades que atuam com o vírus na constituição de ambientes de risco e de vulnerabilidade. Em outros termos,

análises da pandemia centradas no agente patogênico estão por toda parte. Cepas, variantes, contágio, propagação - "novo coronavírus". Aquele vocabulário elitista e tecnocrático da Saúde Global que reduz a complexidade dos processos de saúde, doença e cuidado a indicadores objetivos, transculturais e pretensamente universalizáveis foi sutilmente incorporado ao nosso cotidiano. Mas, tem também as "histórias com gente". É o caso daquelas que nos interessam na antropologia. Nelas, pandemia não é assunto de agente patogênico em si. Importam os efeitos que eles produzem nas nossas relações, identidades e trajetórias. Mais além do vírus, os gestos e atenções; as desilusões e esperanças; as invisibilidades e exclusões, mas também a força e a resistência. É a pandemia em raça, gênero, território e ambientes, das lutas de ontem e do tempo presente, dos vínculos parentais, das redes de cuidado (SEGATA; SEGATA, 2021, p. 12).

Trabalhos etnográficos fazem aparecer muitas pandemias porque colocam em relevo o caráter múltiplo e desigual dos arranjos com vírus. É o caso daqueles que compõem este dossiê. Por diferentes caminhos, eles tensionam as narrativas hegemônicas que se constituíram em tor- 
no do "coronavírus", colocando em evidência a complexidade do que mais compõe com ele a pandemia e os conhecimentos e práticas locais para a sua análise e resposta. Assim, este dossiê trata a pandemia para mais além do vírus. Os trabalhos aqui reunidos avançam na análise da pandemia de covid-19 intersectada com temas como velhice no sertão, territorialidades e prostituição, corpo e deficiência, saberes e práticas de agentes comunitários de saúde, religiões de matriz africana ou a análise de memes sobre a pandemia e isolamento social. Trata-se de artigos que ecoam diferentes experiências e contextos etnográficos, de autores e de autoras e de organizadores e organizadoras do dossiê com vínculo com diferentes instituições brasileiras e do exterior, como a Escola Multicampi de Ciências Médicas - EMCM/UFRN, a UFPB, a UFRGS, a Universidade Presbiteriana Mackenzie, a UnB e a UNSAM/Argentina.

Sobressai no conjunto de artigos que a complexidade da pandemia precisa ser examinada a partir de exercícios descritivos do sensível, da vida vivida, ao invés da exaltação de indicadores de padrão e métricas de avaliação internacional que frequentemente excluem a experiência social. É claro que o volume total de infectados, as proporções entre quem destes adoeceu e precisou de cuidados médicos e em que nível de atenção e o número de mortes e de sobrevivências são informações fundamentais para a extensão e formatos da pandemia. Mas, quando buscamos as memórias e os sentidos deste evento crítico, precisamos "preencher" esses números e tendências com trajetórias, biografias e experiências individuais e coletivas. Em outros termos, faz mais de um ano e meio que "pandemia" virou o tema das nossas vidas. Ela é fonte de medos e de incertezas, de sofrimento pessoal e coletivo, de dores e de perdas e de transformações de rotinas que vão desde práticas de trabalho, lazer, educação e sociabilidade ao funcionamento das instituições. Isto nos mostra como saúde e sociedade não são dimensões estrangeiras entre si. A pandemia é um evento social complexo, e como tal, se realiza sempre em terrenos muitos acidentados da vida cotidiana. O problema é que a natureza episódica e excepcional de uma crise em tempo real, como a pandemia de covid-19, impele a respostas imediatas. Acontece que quase sempre elas tendem a dificultar modelos explicativos locais. Questionar o encapsulamento biomédico da covid-19 executado pelo "coronavírus-centrismo" que modulou a pandemia é um tópico crítico. Políticas da Saúde Global e seus indicadores internacionais negligenciam sensibilidades locais e dificultam a apreensão do seu caráter múltiplo e desigual (ROSENBERG, 1992; PORTO, 2020; GAMLIN; SEGATA; BERRIO, GIBBON; ORTEGA, 2021). É preciso de(s)colonizar a pandemia pois, como não estamos diante de um evento homogêneo, as nossas análises e respostas a ele também não podem ser.

Abrindo o dossiê, o artigo de Raquel Litterio de Bastos, Eduardo Neves Rocha de Brito, Jéssica Farias Dantas Medeiros e Raíssa Thamires Fernandes de Oliveira analisa uma oficina de mamulengos que teve lu- 
gar no município de Caicó, sertão do Rio Grande do Norte. As autoras e o autor do trabalho problematizam, a partir da experiência com esta oficina, questões relativas ao cuidado, à autonomia e ao controle dos idosos - em especial das mulheres sertanejas -, considerados como um dos principais grupos de risco da pandemia de covid-19.

Na sequência, o artigo de Ricardo Mingareli Del Valle aborda o modo como o vínculo entre espaços habitados e agrupamentos humanos formados por profissionais do sexo e clientes constrói vivências qualificadas por códigos-territórios próprios e dispostos em territorialidades. Estas, como mostra o autor, estão sujeitas a constantes transformações pelos contextos sociais vivenciados, como, por exemplo, com as recomendações de distanciamentos e isolamentos sociais e as táticas preventivas para combater a propagação do novo coronavírus. O artigo nos mostra como estas medidas regularam e modificaram as relações urbanas e coletivas como um todo, inclusive as da prostituição, analisando as possibilidades representativas em que a territorialidade da prostituição se constituiu durante o período pandêmico da covid-19.

O terceiro artigo do dossiê, de autoria de Jéferson Alves e de Ceres Víctora (UFRGS), aborda as experiências de pessoas com deficiência (PCD) na pandemia de covid-19 e as estratégias criadas para (sobre) viver ao contexto que se/lhes impõe. Os relatos e os dados apresentados pelos autores tiveram origem em entrevistas e conversas informais realizadas por meios remotos, como o skype e whatsapp e demonstram que a pandemia atinge corpos de maneiras diferentes - mas que os corpos deficientes são atingidos de formas mais perigosas, daí a necessidade de se criar estratégias e técnicas de si para (sobre)viver na/à pandemia. No argumento de Alves e Víctora, isso demonstra a potencialidade, a criatividade e a inventividade dos corpos deficientes, tanto em relação a si mesmos quanto como pontos de contraste e de reflexão acerca da sociedade.

No quarto artigo, Ana Paula Marcelino da Silva, Bruna Carla Cordeiro de Carvalho, Ednalva Maciel e Maria José da Silva Pedro (UFPB) demonstram as experiências locais da pandemia do coronavírus por meio dos relatos de uma agente comunitária de saúde de João Pessoa. São entraves burocráticos sobre quem é ou não profissional de saúde da "linha de frente" da pandemia ou as dificuldades encontradas com relação às informações sobre ela que revelaram como a autoridade dada pela comunidade atravessou as barreiras institucionais dentro dos próprios órgãos. Este processo externalizou o protagonismo da agente comunitária e sua resposta local à inação estatal perante as populações que mais necessitam de atenção.

Na sequência, o artigo de Marília Kosby (UFRGS) esboçou uma cartografia social do campo afrorreligioso na Casas de Religião de Matrizes Africanas no Rio Grande do Sul (Módulo 2) - Pelotas, Rio Grande e Jaguarão, desenvolvidas entre os anos de 2020 e 2021, por demanda do 
Instituto do Patrimônio Histórico e Artístico Nacional-RS. O artigo é fruto de trabalho de cunho qualitativo, baseado em observação participante e realização de questionários e entrevistas. No artigo, as interlocuções com pais e mães de santo trazidas apresentam narrativas sobre os impactos da pandemia de covid-19, suas possíveis causas e efeitos. A autora observa que as casas de religiões de matriz africana trazem em seus fundamentos cosmoecológicos e religiosos premissas que ressoam que a pandemia é sintoma de uma catástrofe muito maior, cuja "cura" nos impele à retomada dos laços que compõem a corresponsabilidade entre os mais distintos entes humanos e não humanos.

O sexto artigo, de autoria de Flavia Demonte e Andrea Mastrangelo (UNSAM/CONICET, Argentina), descreve quase três centenas de memes sobre a covid-19 que circularam pelas redes sociais da internet e, por meio deles, analisa a experiência relativa ao isolamento social preventivo e obrigatório na Argentina de março a novembro de 2020. As autoras reconstruíram narrativas vinculadas com a vida cotidiana durante a pandemia, incluindo a gestão da política sanitária, as práticas preventivas da população, os diferentes sentidos do novo coronavírus e da covid-19 e o impacto do isolamento social na economia familiar, na experiência educativa, na saúde mental e nos olhares sobre o futuro pós-pandemia. No argumento das autoras, os memes, como produtos socioculturais em estreita relação com o contexto social, político, sanitário e cultural/midiático, construíram uma maneira de narrar as incertezas e a reorganização do cotidiano durante a pandemia no contexto argentino.

Por fim, une-se a este dossiê uma entrevista com a antropóloga Soraya Fleischer (DAN/UnB), Como fazer pesquisa antropológica durante uma pandemia?. Nela, encontramos questões metodológicas e éticas, subjetivas e epistemológicas, financeiras e políticas que têm sido discutidas desde quatro anos antes da pandemia de covid-19, quando Fleisher já coordenava uma equipe de pesquisa interessada nas complexidades do cenário da epidemia de Zika em Recife-PE. As reverberações comparativas para a covid-19 e outras epidemias são tópicos essenciais para quem tem o objetivo de pesquisar eventos epidemiológicos e seus impactos sociais, mas também para quem se interessa por pesquisa antropológica de um modo geral.

Enfatiza-se que o investimento deste dossiê em análises e respostas que tensionam os modelos da Saúde Global sobre a pandemia abrem novas frentes para as Ciências Humanas e Sociais, mas também para a população em geral, os setores produtivos e o Estado. É que o olhar antropológico sobre as crises sanitárias não tem o seu enfoque dirigido exatamente aos mecanismos técnico-biológicos que constituem estes eventos, mas para as relações e transformações que provocam nas sociedades (KECK, 2010). O que os trabalhos deste dossiê fazem é colocar em evidência "formas de conhecimento, práticas científicas e políticas 
de intervenção que buscam, em particular, os efeitos dessas articulações para certos sujeitos historicamente situados" (FONSECA; ROHDEN; MACHADO, 2012, p. 07). Além disso, a compreensão apurada da dinâmica de transformações sociais resultantes da pandemia e a avaliação das ações para a sua contenção evidenciam implicações éticas e de direitos humanos que merecem análise crítica sob a ótica das ciências humanas e sociais. Para tanto, é preciso que seja considerada a singularidade das populações implicadas, seus níveis de vulnerabilidade e exposição baseados em sua diversidade e em sua desigualdade (SEGATA, 2020; SINGER; RILKO-BAUER, 2021). Portanto, a pandemia demanda abordagem interdisciplinar e políticas intersetoriais que coloquem em preeminência os conhecimentos e as experiências culturalmente localizadas, incluindo tradição, religiosidade, etnicidade, gênero, idade, relações de trabalho ou distinções socioeconômicas. Como já afirmaram Segata, Schuch, Damo e Victora (2021), se a pandemia não é um evento homogêneo, as respostas a ela também não podem ser.

\section{REFERÊNCIAS}

FONSECA, Claudia; ROHDEN, Fabíola; MACHADO, Paula Sandrine. Antropologia a partir das ciências: reflexões preliminares. In: FONSECA, Claudia; ROHDEN, Fabíola; MACHADO, Paula Sandrine (org.). Ciências na vida: antropologia da ciência em perspectiva. São Paulo: Terceiro Nome, 2012. p. 7-24.

GAMLIN, Jennie; SEGATA, Jean; BERRIO, Lina; GIBBON, Sahra; ORTEGA, Francisco. Centring a critical medical anthropology of covid-19 in global health discourse. BMJ Global Health, n. 6, p. e006132, 2021.

Keck, Frédéric. Un monde grippé. Paris: Flammarion, 2010.

PORTO, Rozeli. Zika vírus e itinerários terapêuticos: os impactos da pós-epidemia no Estado do Rio Grande do Norte. Ilha - Revista de Antropologia, v. 22, p. 169-199, 2020.

ROSENBERG, Charles. Explaining epidemics. Cambridge: Cambridge University Press, 1992.

SEGATA, Jean. Covid-19, biossegurança e antropologia. Horizontes Antropológicos, v. 26, n. 57, p. 275-313, 2020.

SEGATA, Jean; SEGATA, Juliara Borges. Prefácio: muito além do vírus. In: PIMENTA, Denise Nacif; ALMEIDA, Juniele Rabêlo; GARCIA, Lima (org.). (Im)permanências: história oral, mulheres e envelhecimento na pandemia. Rio de Janeiro: Letra \& Voz, 2021. p. 12-17.

SEGATA, Jean; SCHUCH, Patrice; DAMO, Arlei; VÍCTORA, Ceres. A covid-19 e suas múltiplas pandemias. Horizontes Antropológicos, v. 27, n. 59, p. 7-25, 2021. 